ORIGINAL STUDY

\title{
Acoustic rhinometry and rhinomanometry as objective tools for the assessment of nasal patency in nasal septal surgery
}

\author{
Frodita Jakimovska', Marina Davceva Cakar ${ }^{1}$, Dejan Dokic ${ }^{2}$ \\ ${ }^{1}$ University ENT Clinic, Skopje, Macedonia \\ ${ }^{2}$ University Clinic of Respiratory Disease and Allergology, Skopje, Macedonia
}

\begin{abstract}
BACKGROUND. Septal deviations are usually diagnosed by a patient's subjective complaint of nasal stuffiness and a physical examination by the otorhinolaringologist. The decision for surgery is not always based on objective measurements. Acoustic rhinometry and rhinomanometry are objective tools for assessment of nasal patency but is still a controversial subject. In our populations, there are no general accepted methods for screening patients for septal surgery.

OBJECTIVE. To analyse the effectiveness of acoustic rhinometry and rhinomanometry in predicting the outcomes of septoplasty and rhinoseptoplasty and their usefulness in preoperative screening of septal deviations.

MATERIAL AND METHODS. 69 patients were included in this prospective study. Acoustic rhinometry and rhinomanometry were performed before and one year after surgery for the investigation of nasal obstruction. Several parameters were analysed before and after decongestion of the nasal mucosa. VAS (visual analogue scale) was also included for evaluation of the subjective symptom score pre- and postoperatively. After surgery, a short questionnaire was applied to investigate patients' postoperative satisfaction.

RESULTS. The mean subjective scores of nasal patency improved significantly after surgery with $77 \%$. Several parameters of acoustic rhinometry and rhinomanometry were analysed with binary logistic regression, to evaluate the predictive values on the postoperative satisfaction. The preoperative decongested overall MCA (minimal cross-sectional area) on the deviation side, the decongested bilateral MCA and the decongested Flow ratio had significantly the highest impact on the postoperative satisfaction $(\mathrm{p}<0.001)$.

CONCLUSION. Acoustic rhinometry and rhinomanometry as objective tools can serve as objective evidence for the efficacy of septoplasty and rhinoseptoplasty. The parameters of rhinomanometry and anterior rhinometry are useful in the preoperative screening for septal deviations and in predicting postoperative satisfaction between different degrees of nasal septal deviations. KEYWORDS: acoustic rhinometry, rhinomanometry, septal deviation
\end{abstract}

\section{INTRODUCTION}

Nasal septal deviation (NSD) is very often the cause for nasal obstruction ${ }^{1}$. The prevalence of septal deviations has been reported to be up to $80 \%$ in the general population ${ }^{2}$. The diagnosis made by otolaryngologists is not usually based on objective measurements ${ }^{3}$. Nasal obstruction symptoms are subjective and do not always coincide with anterior rhinoscopy or endoscopy findings. Today, patients are often selected for surgery without any objective measurements of the nose $\mathrm{e}^{4}$. Dinis et al. argued that improperly stored indication for septal surgery was one of the major reasons for low patient satisfaction rates ${ }^{5}$. The ENT specialists still have dilemmas whether the septal deformities detected at the anterior rhinoscopy are actually the cause of the patients' symptoms and whether the patient is a suitable candidate for septal surgery ${ }^{6}$. The surgeon's decision for surgery can be easier if the septal deviations are very severe; but, for the mild septal devia- 
tions, the decision on whether or not to operate is still difficult to make, especially after decongestion, when it may look less significant ${ }^{7}$.

The objective tools usually used for the assessment of nasal patency are acoustic rhinometry and rhinomanometry. Rhinomanometry (RMM) assesses nasal airflow and provides a dynamic and functional evaluation. Acoustic rhinometry assesses nasal geometry and provides static and anatomical evaluation ${ }^{8}$. For some authors, AR (acoustic rhinometry) is mandatory in the diagnosis and the evaluation of the treatment effects on nasal obstruction, despite the relatively weak relation between the subjective and objective outcomes. Many studies reported discrepancies between subjective sensation and objective measures of nasal patency ${ }^{9-12}$.

Measurement tools could potentially aid in selecting patients for surgery. Although septoplasty provides adequate correction of septal deviation, patients are not always satisfied with the postoperative results. Nasal airway blockage due to septal deviation may be present in various degrees of severity and the operation is indicated to improve quality of life through improvement of symptoms (nasal obstruction, mouth breathing, snoring, apnea, rhinosinusitis, etc. $)^{13,14}$. Some tools, such as questionnaires, which assess the quality of life, have become a gold standard and came to replace the simplistic way used to ask the patient whether they had any improvement after surgery ${ }^{15}$. In many cases, the nasal septum may appear straight after the operation, but the patient may be more or less dissatisfied with the postoperative airway.

The objective of this study was to analyse the effectiveness of acoustic rhinometry and rhinomanometry in predicting outcomes of septoplasty and rhinoseptoplasty and their usefulness in preoperative screening of septal deviations.

\section{MATERIAL AND METHODS}

This prospective study has been done on 69 patients presented at the University ENT Clinic, seeking for septoplasty and rhinoseptoplasty, between November 2011 and June 2014. All 69 patients had nasal obstruction complaints for more than 6 months. Patients were asked about their medical history and underwent anterior rhinoscopic examination. The surgical decision was based on the clinical judgement and the persistence of nasal obstruction for more than 6 months.

The objective tests (AR and RMM) were performed after the decision for surgery was taken. Acoustic rhinometry (Acoustic Rhinometer A1; GM Instruments, U.K.) and anterior rhinomanometry (Interacoustic, Denmark) were used according to the guidelines defined by the Standardization Committee. Both nasal cavities were decongested with 2 puffs of $0.05 \%$ oxymetazoline after 15 minutes of rest. The measurements were performed before and 15 minutes after decongestion. The mean value of three measurements was calculated. Unilateral minimal cross-sectional area MCA (the smallest part in the nasal crosssectional area in the nasal meatus) and bilateral minimal cross-sectional area (MCA bilateralis) were measured with acoustic rhinometry. Unilateral and bilateral nasal flow and flow ratio were measured with anterior rhinomanometry.

Subjective symptoms of nasal obstruction before and after surgery were evaluated on a visual analogue scale, and classified as mild, moderate, severe or very severe. Patients reported a score on a scale of 0 (excellent, unobstructed breathing) to 10 (totally obstructed). Follow-up visit was arranged after 12 months.

Patients who suffered from allergic rhinitis, tumors, nasal polyps, nasal septal perforation, complete nasal obstruction in one side, hypothyroidism and those who took aspirin were excluded from the study.

The degree of deviated septum in anterior rhinoscopy was classified as mild, moderate, severe and very severe. Mild deviations were classified if $1 / 3$ of nasal cavity was obstructed, moderate $1 / 2$, severe $2 / 3$ and very severe if $3 / 3$ or more of the nasal cavity was obstructed.

During the postoperative visits, 65 of the 69 patients underwent an extensive subjective analysis of nasal patency and objective evaluations with AR and RMM measurements. After surgery, a short questionnaire was applied to investigate patients' postoperative satisfaction (very high, high, moderate and low).

\section{Statistical analysis}

Statistical assessments were performed using the SPSS software (SPSS version 18). The paired t-test was used to determine differences of VAS score before and after surgery. The medians and interquartile intervals were used to analyse the intercavital differences of AR and RMM parameters in deviated and wide nasal cavities before and after surgery. The binary logistic regression analysis was applied to analyse the preoperative parameters on the postoperative satisfaction and ROC curves in determining sensitivity, specificity and optimal cut-off values for AR and RMM study parameters.

\section{RESULTS}

Sixty-nine patients were enrolled in the study and completed the preoperative evaluation. Sixty-five patients of the total sixty-nine completed the postoperative evaluation during the follow-up visit performed after 12 months. The mean average age was $24.7 \pm 9.1$ 
years with $39(56.5 \%)$ females and $30(43.5 \%)$ males.

The evaluation tools were applied to 65 patients, those who were regularly present at the follow-up visits. The parameters MCA of $0.49 \mathrm{~m}^{2}$ and Flow of 500 $\mathrm{ml} / \mathrm{min}$ after decongestion on the unilateral side were estimated as an optimal cut-off in selecting the patients for functional surgery and predizting postoperative satisfaction. The patients assessed their subjective nasal symptom score using a visual analogue scale (VAS) before and after decongestion, pre- and postoperatively (Table 1 ).

The preoperative and postoperative differences in the subjective breathing scores were analysed with the paired t-test (Table 1).

After septoplasty and rhinoseptoplasty, the overall total subjective breathing score significantly improved by 2.62 points $(77.4 \%$ improvement $)$ compared with the preoperative value $(p=0.000)$ (Table 1$)$. The over- all subjective breathing score was correlated with the subjective improvement on the right and left sides by $41.5 \%$ and $53.1 \%$, respectively $(\mathrm{p}=0.0000)$ (Table 1 ).

The classification of the parameters values in quartiles helps the surgeon define the intercavital differences between the deviated and the wider sides and the percentage of changes.

Postoperative medians and interquartile intervals of post-decongestion overall MCA (AR parameter) and Flow (rhinomanometry parameter) values increased significantly on the deviation side and decreased significantly on the wider side. There was not a statistical significance of non-decongested MCA parameters on the wide side (Table 2 ).

Preoperative medians and interquartile intervals of MCA and Flow parameters on the deviation side were analysed according to the degree of deviation in anterior rhinoscopy (Table 3 ).

Table 1

Subjective breathing score - VAS

\begin{tabular}{|c|c|c|c|c|c|c|}
\hline \multirow{2}{*}{ VAS } & & Preoperative & Postoperative & & toperative & \multirow{2}{*}{ P Value } \\
\hline & & \multicolumn{2}{|c|}{ Mean } & \% Difference & $\%$ of the improved subjects & \\
\hline \multirow{3}{*}{ Pre-Decongestion } & Right & 3.77 & 0.56 & -85.0 & 61.5 & $P=0.000 \mathrm{~S}$ \\
\hline & Left & 4.57 & 0.72 & -84.3 & 81.3 & $P=0.000 S$ \\
\hline & Total & 4.45 & 0.47 & -89.4 & 92.3 & $P=0.000 S$ \\
\hline \multirow{3}{*}{ Post-Decongestion } & Right & 2.42 & 0.15 & -93.6 & 41.5 & $P=0.000 S$ \\
\hline & Left & 3.18 & 0.31 & -90.3 & 53.1 & $P=0.000 S$ \\
\hline & Total & 2.86 & 0.24 & -91.7 & 77.4 & $P=0.000 S$ \\
\hline
\end{tabular}

Table 2

Medians and interquartile intervals of acoustic rhinometry (AR) and rhinomanometry (RMM) parameters

\begin{tabular}{|c|c|c|c|c|}
\hline $\begin{array}{l}\text { AR and RMM } \\
\text { Parameters }\end{array}$ & $\begin{array}{c}\text { Preoperative Median } \\
(25-75 \%) \\
\end{array}$ & $\begin{array}{c}\text { Postoperative Median } \\
(25-75 \%) \\
\end{array}$ & $\begin{array}{l}\text { Changes } \\
(25-75 \%) \\
\end{array}$ & t-Test \\
\hline \multicolumn{5}{|l|}{ MCA pre-decongestion } \\
\hline Deviation side & $0.25(0.15-0.40)$ & $0.48(0.42-0.50)$ & $0.17(0.06-0.27)$ & $P<0.0001 S$ \\
\hline Wide side & $0.49(0.41-0.62)$ & $0.50(0.48-0.55)$ & $0.06(0.0-0.27)$ & $\mathrm{P}=0.392 \mathrm{NS}$ \\
\hline \multicolumn{5}{|l|}{ MCA post-decongestion } \\
\hline Deviation side & $0.35(0.25-0.49)$ & $0.51(0.49-0.54)$ & $+0.01(-0.12-0.07)$ & $P<0.0001 S$ \\
\hline Wide side & $0.48(0.42-0.50)$ & $0.55(0.53-0.60)$ & $-0.02(-0.24-0.02)$ & $\mathrm{P}<0.0001 \mathrm{~S}$ \\
\hline \multicolumn{5}{|l|}{ Flow pre-decongestion } \\
\hline Deviation side & $130(44-294)$ & $485(384-512)$ & $+253(92-407)$ & $\mathrm{P}<0.0001 \mathrm{~S}$ \\
\hline Wide side & $390(272-483)$ & $515(465-550)$ & $+66(-27-137)$ & $\mathrm{P}<0.0001 \mathrm{~S}$ \\
\hline \multicolumn{5}{|l|}{ Flow post-decongestion } \\
\hline Deviation side & $195(68-370)$ & $511(495-529)$ & +120 (49-218) & $\mathrm{P}<0.0001 \mathrm{~S}$ \\
\hline Wide side & $506(423-586)$ & $548(523-589)$ & $-0.93(-1.04-0.68)$ & $P<0.010 S$ \\
\hline
\end{tabular}


There was a significant correlation between anterior rhinoscopy (the degree of deviation) and MCA on the pre-decongested deviation side (Spearman correlation coefficient, $\mathrm{r}=-0.59, \mathrm{p}<0.05)$ and the post-decongested deviated side (Spearman correlation coefficient $\mathrm{r}=-0.68, \mathrm{p}<0.05)$. There was a significant correlation between anterior rhinoscopy (the degree of deviation) and Flow at 150 Pascal on the pre-decongested deviation side (Spearman correlation coefficient, $\mathrm{r}=-0.75, \mathrm{p}<0.05)$ and the post-decongested deviated side (Spearman correlation coefficient $r=-0.80$, $\mathrm{p}<0.05$ ) (Table 3).

The Wald $\mathrm{x}^{2}$ statistical test and the binary logistic regression analysis were applied to determine the relationships of the preoperative values of AR and RMM parameters in predicting postoperative satisfaction.

All 65 patients were divided in two cohorts according to the degree of deviations: one cohort with milder deviations and the other cohort with very severe deviations. Six parameters with the highest predictive value were analysed in the group of all patients as well as in the two cohorts with the binary logistic regression analysis. The post-decongestion overall MCA on the deviation side and the post-decongestion MCA ratio had the highest predictive values both in all deviations and in the cohort with milder deviation $(p<0.001)$. The RMM parameters of the post-decongestion Flow ratio had the highest impact on the postoperative satisfaction both in all deviations and in the cohort with milder deviation $(\mathrm{p}<0.001)$ (Table 4$)$.

ROC analysis was applied to search for on sensitivity and specificity of the two devices (AR and RMM) and to estimate the best preoperative parameters in predicting postoperative satisfaction. The AR parameters (the post-decongestion overall MCA on the deviated side), the RMM parameters (the post-decongestion flow ratio) and the finding of the anterior rhinoscopy (degree of deviations classified as very severe, severe, moderate or mild) were included in the analysis. Specificity and sensitivity for the MCA and Flow ratio was $82 \%$, respectively $64 \%$. There were not statistically significant results for the values of the anterior rhinoscopy (Figure 1).

The binary logistic regression analysis was applied to evaluate the preoperative parameters with high impacts on the postoperative satisfaction.

Table 3

Medians and interquartile intervals of preoperative MCA and Flow according to the degree of deviation in anterior rhinoscopy

\begin{tabular}{cccc}
\hline \multicolumn{2}{c}{ Degree of deviation in anterior rhinoscopy } & $\begin{array}{c}\text { MCA, Deviation side (cm2) } \\
\text { Median (25-75\%) }\end{array}$ & $\begin{array}{c}\text { Flow, Deviation side (mL/min) } \\
\text { Median (25-75\%) }\end{array}$ \\
\hline \multirow{2}{*}{ Very severe $n=23$} & Pre-decongested & $0.15(0.14-0.25)$ & $50(41-120)$ \\
\cline { 2 - 4 } Severe $\mathrm{n}=10$ & Post-decongested & $0.28(0.19-0.36)$ & $144(53-219)$ \\
\hline \multirow{2}{*}{ Moderate or less $\mathrm{n}=36$} & Pre-decongested & $0.33(0.25-0.36)$ & $205(89-219)$ \\
\hline & Post-decongested & $0.42(0.31-0.42)$ & $240(134-248)$ \\
\hline
\end{tabular}

Table 4

Preoperative acoustic rhinomerty (AR) and rhinomanometry (RMM) parameters with the highest impacts in predicting postoperative satisfaction in all patients and in the two cohorts (binary logistic regression analysis)

\begin{tabular}{|c|c|c|c|c|c|c|}
\hline \multirow[t]{2}{*}{ Preoperative AR and RMM parameters } & \multicolumn{2}{|c|}{ All patients $(n=65)$} & \multicolumn{2}{|c|}{$\begin{array}{l}\text { Cohort with milder deviation } \\
\qquad(n=45)\end{array}$} & \multicolumn{2}{|c|}{$\begin{array}{l}\text { Cohort with very severe deviation } \\
\qquad(n=20)\end{array}$} \\
\hline & Wald $x^{2}$ & p (Sig.) & Wald $x^{2}$ & p (Sig.) & Wald $x^{2}$ & p (Sig.) \\
\hline MCA, deviation side, post-decongested & 12.34 & 0.001 & 11.26 & 0.001 & 0.00 & NS \\
\hline MCA, bilateral, post-decongested & 11.23 & 0.01 & 9.72 & 0.01 & 0.00 & NS \\
\hline MCA ratio, post-decongested & 22.84 & 0.001 & 21.46 & 0.001 & 0.00 & NS \\
\hline Flow ratio, post-decongested & 23.57 & 0.001 & 22.56 & 0.001 & 0.00 & NS \\
\hline Flow, deviation side, pre-decongested & 8.27 & 0.01 & 6.58 & 0.01 & 0.02 & NS \\
\hline Flow, deviation side, post-decongested & 0.00 & NS & 0.00 & NS & 0.00 & NS \\
\hline
\end{tabular}




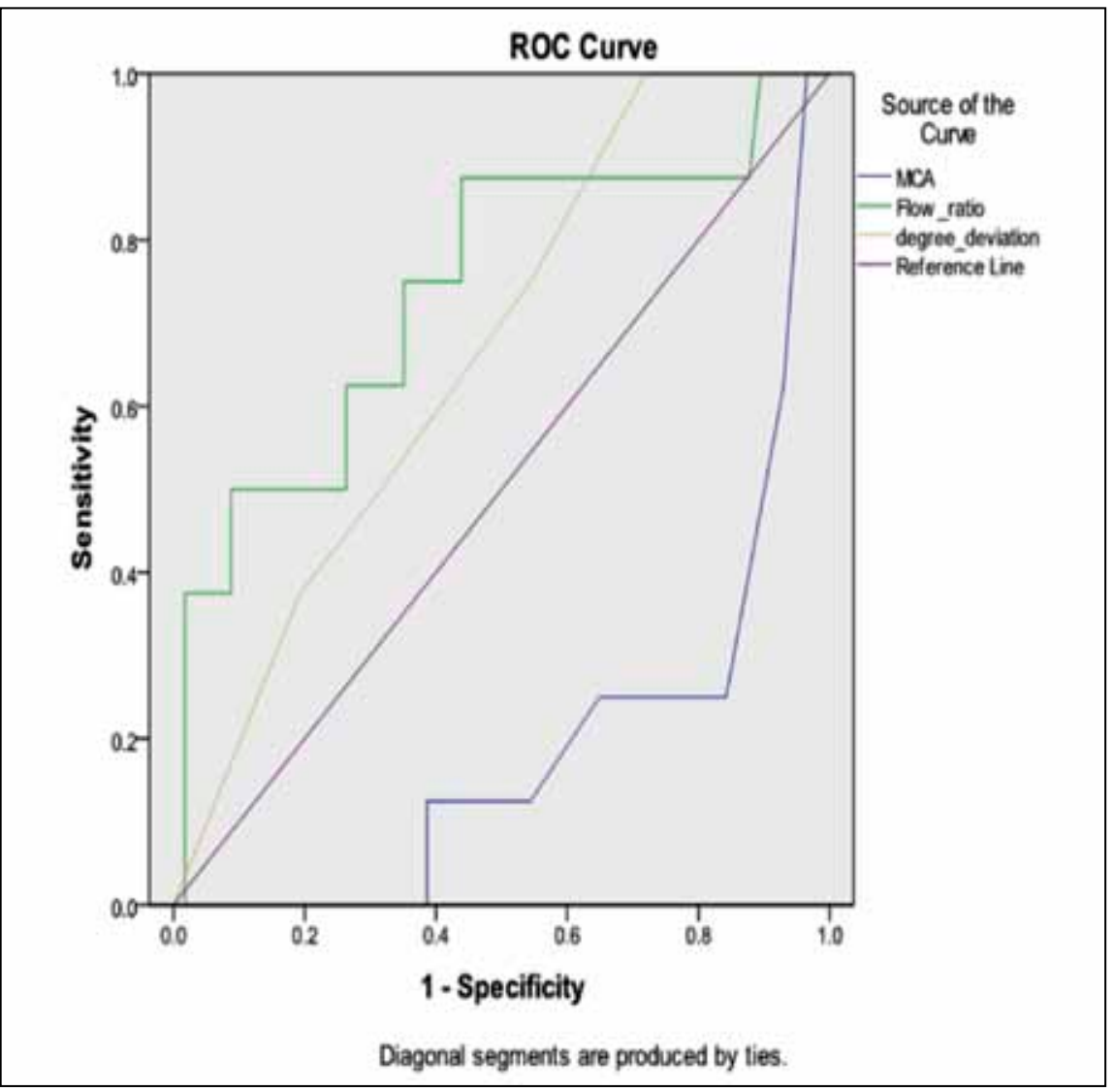

Figure 1 ROC curves for preoperative parameters in predicting postoperative satisfaction

All 65 patients were divided in two cohorts according to predicted values of preoperative parameters on postoperative satisfaction: one cohort as very high or high satisfaction and the other cohort as moderate or low satisfaction. Mann-Whitney test was used to analyse the statistically significant difference between the two groups. The preoperative values of the post-decongested overall MCA on the deviated side, post-decongested bilateral MCA and post-decongested Flow ratio showed a statistically significant difference between parameters with high impacts on postoperative satisfaction between the two cohorts (Table 5).

\section{DISCUSSIONS}

Patients with chronic nasal obstruction are often a challenge for the surgeon. During the initial preoperative evaluation, the correlation between subjective assessment of nasal airflow and actual functional and skeletal characteristics of the patient may be difficult to establish ${ }^{16-18}$. Nasal septal deviation diagnosed by the otolaryngologists is not usually based on objective measurements and selection criteria for septal surgery are often based on the anterior rhinoscopy findings $^{18,19}$.

Table 5

Preoperative AR and RMM parameters with high impacts on postoperative satisfaction of the cohorts

\begin{tabular}{cccc}
\hline \multirow{2}{*}{$\begin{array}{c}\text { Preoperative parameters with high impacts on } \\
\text { postoperative satisfaction }\end{array}$} & \multicolumn{2}{c}{ Postoperative satisfaction } & $\begin{array}{c}\text { Significance between groups } \\
\text { (Mann-Whitney test }\end{array}$ \\
\cline { 2 - 3 } & $\begin{array}{c}\text { very high } / \text { high } \mathbf{n}=\mathbf{5 7} \\
\text { Median (25-75\%) }\end{array}$ & $\begin{array}{c}\text { moderate / low } \mathbf{n = 8} \\
\text { Median (25-75\%) }\end{array}$ & $\mathrm{P}<0.005$ \\
\hline MCA, deviation side, post-decongested & $0.29(0.18-0.42)$ & $0.14(0.10-0.22)$ & $P<0.0001$ \\
\hline MCA, bilateral, post-decongested & $1.09(0.95-1.22)$ & $0.76(0.68-0.84)$ & $P<0.029$ \\
\hline Flow ratio, post-decongested & $1: 1.3(1.10-1.67)$ & $1: 1.9(1.32-3.80)$ & NS \\
\hline Flow, deviation side, pre-decongested & $140(44-320)$ & $46(39-134)$ & \\
\hline
\end{tabular}


In this study, the decision for surgery was based on physical examination and the symptom of nasal obstruction. The symptom of nasal obstruction is considered a subjective symptom. The objective tests of AR and RMM were performed after the decision for surgery was taken. An MCA after decongestion of $0.49 \mathrm{~m}^{2}$ on the narrow side was estimated as an optimal cut-off for predicting postoperative satisfaction.

The VAS score the patient reported during the preoperative examination was a simple and reliable subjective tool in predicting postoperative results for those with nasal septal deviation.

The postoperative subjective score in all 65 patients submitted to surgery and who were evaluated postoperatively was higher than their preoperative subjective score. The percentage of the mean difference between the pre- and postoperative subjective breathing scores was higher $(91.7 \%)$ in this study, than the percentage of the mean difference (38\%) in the study of Zoumalan and Constantinidis ${ }^{20}$.

The classification of the parameters values in quartiles helps the surgeon define which are the patients who can most benefit from the surgery.

In our study, the medians and interquartile intervals of overall MCA and Flow values increased significantly on the deviation side and decreased significantly on the wider side before and after decongestion, pre- and postoperatively, similar to the study of Pirila and Tikanto ${ }^{21}$.

Grymer in her study found a highly significant correlation between the minimal cross-sectional area and the subjective feeling of nasal patency, before and after surgery. MCA parameter was significantly smaller in dissatisfied subjects postoperatively compared to satisfied patients $\left(0.45\right.$ and $0.74 \mathrm{~cm}^{2}$, respectively) $)^{22}$.

In the present study, the medians and interquartile intervals of MCA and Flow parameters in the deviations group determined by anterior rhinoscopy increase after decongestion in all groups. The median of the MCA value in the group of severe deviations was $0.27 \mathrm{~cm}^{2}$ on the deviated side. In the study of Stucs and Clement, the post-decongestion median overall MCA on the deviation side was found to be $0.25 \mathrm{~cm}^{2}$ in the group with a severe deviation (occluding more than one half of the nasal cavity) and $0.37 \mathrm{~cm}^{2}$ in moderate deviations. Those values are similar to the results from the present study ${ }^{23}$.

Broms et al. reported a better outcome after septoplasty in patients with high NAR (nasal airway resistance) preoperatively ${ }^{24}$. Jessen and Malm also observed a large number of satisfied patients after septoplasty $(81 \%)$ and the decision to perform surgery was based on a pathological NAR preoperatively. An even larger number were improved according to
RMM $(94 \%)^{25,26}$. Sipilä et al. showed more benefit from surgery in patients which NAR was high preoperatively ${ }^{27}$. In another study, Sipila reported that, the group of patients where preoperative NAR was normal, the success rate was $65 \%$, but in the group with pathological NAR, $85 \%$ of patients were satisfied with their outcome ${ }^{28}$.

Kemker analysed the effectiveness of septoplasty on acoustic rhinometry results and reported a considerable increase in the nasal cross-sectional area and volume after surgery, particularly in the more posterior portions. He did not found a relationship between objective tests results and clinical findings or symptoms ${ }^{29}$.

Pirila et al. reported a decrease of the cross-sectional area in MCA1 (the smallest part in the nasal cross-sectional area in the nasal meatus) on the side with septal deviation and a significant decrease on the opposite side, both before and after using a decongestant after surgery. During the evaluation of the MCA2 (the second smallest nasal cross-sectional area in the nasal meatus), Pirilia observed a significant increase on the deviated side before and after using a decongestant following surgery; however, the increase on the other side was not considerable ${ }^{21}$. Also, Lio in his study confirmed an improvement in resistance of the cross-sectional area on the narrower side after septoplasty, while no variations were witnessed on the wider side ${ }^{30}$.

The authors of the present study showed that six selected preoperative AR and RMM parameters had a statistically significant impact on predicting postoperative satisfaction in all patients and in both cohorts (cohort with very severe deviations and cohort with milder deviations) (Table 4). The ROC curves in Figure 1 showed high percentage of sensitivity/specificity for cut-off values of both parameters (MCA and Flow ratio). The medians for three selected preoperative parameters (MCA on deviated side, bilateral MCA and post-decongestion Flow ratio) in the two postoperative satisfaction groups (very high/high and moderate/ low) were statistically significant. The medians for the preoperative Flow parameter on the pre-decongested deviated side did not show statistically significant results in the two postoperative satisfaction groups.

Pirila and Tikanto evaluated in their study 10 preoperative parameters with highest impact on the postoperative satisfaction. They found that the optimal cut-off for MCA after decongestion for predicting postoperative satisfaction was $0.40 \mathrm{~m}^{3}$ on the narrow side. For AR, as well as for RMM, both sensitivity and specificity were higher regarding the prediction of postoperative satisfaction than was the case for anterior rhinoscopy. The authors confirmed that medians for four selected preoperative parameters were statistically significant in the two postoperative satisfaction groups ${ }^{31}$. 
Boyce and Eccles concluded in their study that all patients with severe septal deviations can be identified by using rhinoscopy; the problem was represented by the milder deviations and, as a solution, they proposed a parameter measuring the lateral difference between cavities $^{32}$. From our point of view, this is a different issue, but it would be a good challenge to study the lateral difference between cavities by RMM and AR parameters in patients proposed for functional and aesthetic surgery.

\section{CONCLUSIONS}

The anterior rhinoscopy is sufficient in diagnosing the severe deviations located in the anterior parts of the nasal cavity. Rhinomanometry and especially anterior rhinometry are objective tools in the determination of milder deviations, which cause more dilemmas between surgeons in selecting the patients with nasal obstruction for functional nasal surgery. The parameters of rhinomanometry and anterior rhinometry are useful in preoperative screening for septal deviations and in predicting postoperative satisfaction between different degrees of nasal septal deviations.

Conflict of interest: The authors have no conflict of interest.

Contribution of authors: All authors have equally contributed to this work.

\section{REFERENCES}

1. Stewart M.G., Smith T.L., Weaver E.M., et al. - Outcomes after nasal septoplasty: results from the Nasal Obstruction Septoplasty Effectiveness (NOSE) study. Otolaryngol Head Neck Surg., 2004;130(3):283-290.

2. Gray L.P. - Deviated nasal septum. Incidence and etiology. Ann Otol Rhinol Laryngol Suppl., 1978;87(3 Pt 3Suppl 50):3-20.

3. Aziz T., Biron L.V., Ansari K., Flores-Mir C. - Measurement tools for the diagnosis of nasal septal deviation: a systematic review. J Otolaryngol Head Neck Surg., 2014;43:1-11. doi: 10.1186/1916-021643-11.

4. Toyserkani N.M., Frisch T., von Buchwald C. - Postoperative improvement in acoustic rhinometry measurements after septoplasty correlates with long-term satisfaction. Rhinology, 2013;51(2):171-175. doi: 10.4193/Rhino12.163.

5. Dinis P.B., Haider H. - Septoplasty: long-term evaluation of results. Am J Otolaryngol., 2002;23(2):85-90.

6. Skoloudik L., Vokurka J., Zborayova K., Celakovsky P., Kucera M., Ryska A. - Cytology of the nasal mucosa after total laryngectomy. Acta Otolaryngol., 2009;129(11):1262-1265. doi: 10.3109/ 00016480802654398.

7. Holmström M. - The use of objective measures in selecting patients for septal surgery. Rhinology, 2010;48(4):387-393. doi: 10.4193/ Rhino10.072.
8. Tombu S., Daele J., Lefebvre P. - Rhinomanometry and acoustic rhinometry in rhinoplasty. B-ENT, 2010;6(Suppl 15):3-11.

9. Andre R.F., Vuyk H.D., Ahmed A., Graamans K., Nolst Trenite G.J. Correlation between subjective and objective evaluation of the nasal airway. A systematic review of the highest level of evidence. Clin Otolaryngol., 2009;34(6):518-525. doi: $10.1111 / \mathrm{j} .1749$ 4486.2009.02042.x.

10. Kahveci O.K., Miman M.C., Yucel A., Yucedag F., Okur E., Altuntas A. - The efficiency of Nose Obstruction Symptom Evaluation (NOSE) scale on patients with nasal septal deviation. Auris Nasus Larynx., 2012;39(3):275-279. doi: 10.1016/j.anl.2011.08.006. Epub 2011 Aug 31 .

11. Larsson C., Millqvist E., Bende M. - Relationship between subjective nasal stuffiness and nasal patency measured by acoustic rhinometry. Am J Rhinol., 2001;15(6):403-405

12. Vicheva D. - Measurement of the nose with acoustic rhinometry. Medical review, 2004;Vol.XL(3):69-73.

13. Frank-Ito D.O., Kimbell J.S., Laud P., Garcia G.J., Rhee J.S. - Predicting post-surgery nasal physiology with computational modeling: current challenges and limitations. Otolaryngol Head Neck Surg., 2014;151(5):751-759. doi: 10.1177/0194599814547497. Epub 2014 Aug 28.

14. Vicheva D. - Investigation in subjects without nasal symptoms. Turkish Journal of Rhinology, 2008;1 (1):5-7.

15. Mckiernan D.C., Banfield G., Kumar R., Hinton A.E. - Patient benefit from functional and cosmetic rhinoplasty. Clin Otolaryngol., 2001;26(1):50-52. doi: 10.1046/j.1365-2273.2001.00427.x.

16. Lam D.J., James K.T., Weaver E.M. - Comparison of anatomic, physiological, and subjective measures of the nasal airway. Am J Rhinol., 2006;20(5):463-470.

17. Rhee J.S., Poetker D.M., Smith T.L., Bustillo A., Burzynski M., Davis R.E. - Nasal valve surgery improves disease-specific quality of life. Laryngoscope, 2005;115(3):437-440.

18. Vicheva D. - Acoustic rhinometry. Monography. Publishing House "BOYKING", Plovdiv, 2003.

19. Mlynski G. - Surgery of the nasal septum. Facial Plast Surg., 2006;22(4):223-229.

20. Zoumalan R.A., Constantinides M. - Subjective and objective improvement in breathing after rhinoplasty. Arch Facial Plast Surg., 2012;14(6):423-428. doi: 10.1001/archfacial.2012.665.

21. Pirila T., Tikanto J. - Unilateral and bilateral effects of nasal septum surgery demonstrated with acoustic rhinometry, rhinomanometry, and subjective assessment. Am J Rhinol., 2001;15(2):127-133.

22. Grymer L.F., Hilberg O., Elbrond O., Pedersen O.F. - Acoustic rhinometry: evaluation of the nasal cavity with septal deviations, before and after septoplasty. Laryngoscope, 1989;99(11):1180-1187.

23. Szucs E., Clement P.A. - Acoustic rhinometry and rhinomanometry in the evaluation of nasal patency of patients with nasal septal deviation. Am J Rhinol., 1989;12(5):345-352.

24. Broms P. - Rhinomanometry. III. Procedures and criteria for distinction between skeletal stenosis and mucosal swelling. Acta Otolaryngol., 1982;94(3-4):361-370.

25. Jessen M., Malm L. - The importance of nasal airway resistance and nasal symptoms in the selection of patients for septoplasty. Rhinology, 1984;22(3):157-164.

26. Jessen M., Ivarsson A., Malm L. - Nasal airway resistance and symptoms after functional septoplasty: comparison of findings at 9 months and 9 years. Clin Otolaryngol Allied Sci., 1989;14(3):231-234.

27. Sipilä J.I., Suonpää J.T., Kortekangas A.E., Laippala P.T. - 
Rhinomanometry before Septoplasty: An Approach to Clinical Material with Diverse Nasal Symptoms. Am J Rhinol., 1992;6(1):17- 22.

28. Sipila J., Suonpaa J. - A prospective study using rhinomanometry and patient clinical satisfaction to determine if objective measurements of nasal airway resistance can improve the quality septoplasty. Eur Arch Otorhinolaryngol., 1997;254(8):387-390.

29. Kemker B., Liu X., Gungor A., Moinuddin R., Corey J.P. - Effect of nasal surgery on the nasal cavity as determined by acoustic rhinometry. Otolaryngol Head Neck Surg., 1999;121(5):567-571.
30. Lio H.J. - Outcome after nasal septoplasty. Otolaryngol Clin N Am., 2010;52:205-221.

31. Pirila T., Tikanto J. - Acoustic rhinometry and rhinomanometry in the preoperative screening of septal surgery patients. Am J Rhinol Allergy, 2009;23:605-609.

32. Boyce J.M., Eccles R. - Assessement of subjective scales for selection of patients for nasal septal surgery. Clin Otolaryngol., 2006;31:297-302. 